\title{
AN OPTIMIZATION MODEL FOR AUTOMOBILE MIXED ASSEMBLY LINE UNDER MULTIPLE CONSTRAINS
}

\author{
He, S. H. ${ }^{*, \#}$; Li, X. D. ; Wang, Y.* \& Zhu, H. H. ${ }^{* * *}$ \\ *Linyi University, Linyi 276000, China \\ ** Linyi Branch Transportation Planning and Design Limited Company, Linyi 276000, China \\ ${ }^{* * *}$ Wuhan University of Technology, Wuhan 430063, China \\ E-Mail: heshouhui@lyu.edu.cn $\left({ }^{\#}\right.$ Corresponding author); lixiaodong@lyu.edu.cn, \\ 314402389@qq.com, hhzhu@whut.edu.cn
}

\begin{abstract}
To solve the problems in planning and design of automobile mixed-model assembly line, this paper puts forward the improved genetic algorithm-based equilibrium optimization algorithm for the automobile mixed assembly line and establishes corresponding theoretical model. The convergence and feasibility of the model are analysed, and the optimization model presented in this paper is verified by the assembling situation of the actual assembly line of an automobile door. The research conclusions are as follows. The optimized scheduling mathematical model under multiple constrains of the automobile assembly line was established and improvements were made to the traditional genetic algorithm. Self-adaptive genetic operator was added to the original model. The performance verification indicated that the time consumption of CPU in the proposed improved algorithm is much less, and its maximum load is larger, so it has better convergence compared with traditional genetic algorithm. The improved optimal algorithm of automobile mixed ASSEMBLY LINE was verified taking into consideration such constraint conditions as the proportion of a single product put into assembly line, staffing, and balance of the left door and right door. It is found that the overall balance efficiency is about $92 \%$, reaching the standard for leaving factory. When the proportion of a single product that was put into production gradually rises, the overall time-consumption of the whole assembly line becomes shorter and shorter and the balance efficiency of the mixed assembly line presents a "U-shape" variation trend, first decreasing and then increasing. The growth of workers doesn't have an obvious impact on the assembling time consumption.

(Received, processed and accepted by the Chinese Representative Office.)
\end{abstract}

Key Words: Automobile, Mixed Assembly Line, Constraint Conditions, Optimization, Improved Genetic Algorithm

\section{INTRODUCTION}

The automobile industry has been developing for a hundred years, featuring equipment concentration, large number of workers, centralized equipment stacking, etc. The type of automobile also changes from single gasoline power auto to hybrid, pure electric and other types [1-5]. As the global economic contacts become more and more frequent, the automobile industry is faced with competition in the global market, which requires the enterprises to constantly make innovation, optimize the production efficiency of the automobile assembly line and enhance service level to meet the needs of different customers.

The mass production of a single variety of automobile has passed, and only when the diversified needs of customers are met, can the auto enterprises keep sustainable development. Multispecies mixed ASSEMBLY LINEs are the auto production and processing way adopted by all large auto enterprises currently. The production is mainly influenced by the assembling sequence constraint, time tempo constraint, and alterable task time, concurrent assembling staffing, and other factors [6-10]. Different auto appearances, inner trims, power system, etc. are available to customers by adopting the mixed-model assembly line. Meanwhile, the planning and design of the mixed-model assembly line have become a 
difficulty during the auto production process. The adaptability and assembly coordination of different auto parts shall be given into full consideration during the planning.

The current balanced optimization design of automobile mixed ASSEMBLY LINE is realized by simulation modelling. After establishing the overall planning and relevant constraint conditions of the assembly line, the parameters of each subsystem module and relevant technical process are confirmed and the optimal scheduling of the assembly line is finally achieved. Traditional modelling methods include linear programming method and dynamic programming method [11-12], whose calculated quantity and time consumption are too large, and the calculation results are not in line with the actual situation. Researchers then gradually developed the mathematical theory-based modelling, Petri net method, and activity cycle diagram [13-17]. With the establishment of the mixed ASSEMBLY LINE, its complexity can't be simply described using analytic method or Petri net.

In recent years, some scholars have introduced biology, artificial intelligence and other disciplines into the optimal scheduling of the assembly line, realizing interdisciplinarity innovation and inventing many methods including neural network method, basic genetic algorithm, emergency search method, etc. [18-23]. All the above algorithms have intelligent learning ability, and can solve nonlinear complex problems, therefore they have been widely used in the optimization scheduling of the actual automobile assembly line. However, there are few relevant studies on the balanced optimization design of the automobile mixed ASSEMBLY LINE.

Targeting at the difficulties in the planning and design of automobile mixed-model assembly line, this paper puts forward the improved genetic algorithm-based equilibrium optimization algorithm for the automobile mixed assembly line and establishes corresponding theoretical model. The convergence and feasibility of the model are analysed, and the optimization model presented in this paper is verified by the assembling situation of the actual assembly line of an automobile door.

\section{MATHEMATIC MODEL OF AUTOMOBILE MIXED ASSEMBLY LINE}

The assembly process of the finished automobile in traditional auto enterprises are shown in Fig. 1. It can be seen from the figure that the process mainly includes automotive body panel stamping, body welding, painting, power system and inner trim installation, performance test and off line.

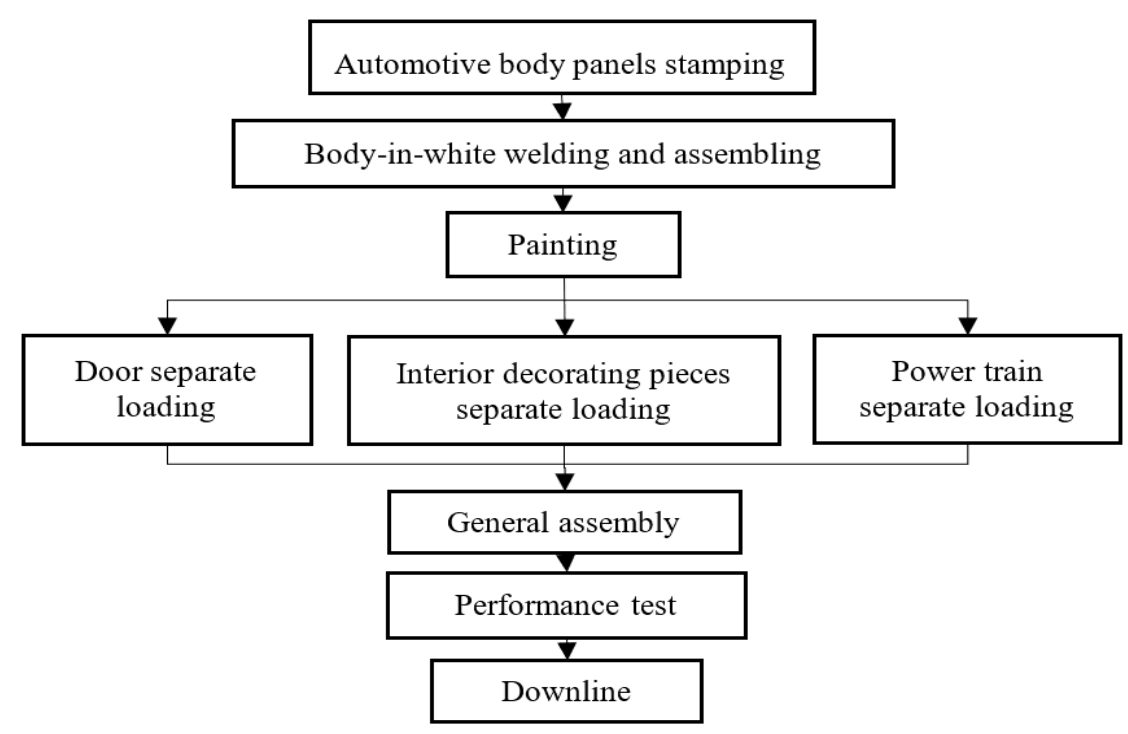

Figure 1: Schematic diagram of technological process of automobile assemblage. 
The optimization of the assembly line mainly covers achieving balance of the flow assembly line, algorithm improvement, and mathematical description of different constraints.

The optimal goals of automobile assembly line generally include setting the minimum number of workstations, minimize the assembling rhythm, or optimize the task load of the assembly line. At present, most automobile assembly lines adopt the scheduling method of optimizing task load, whose mathematical model can be expressed as:

$$
\min S_{l}=\sqrt{\sum_{k=1}^{m} \max \left(t\left(S_{k}\right)-c\right)^{2}}
$$

Its constraint conditions are as follows:

$$
\left\{\begin{array}{l}
S_{i} \cap S_{j}=\varnothing, i \neq j, i, j=1,2,3, \ldots, m \\
\bigcup_{k=1}^{m} S_{k}=E \\
\forall i \in S_{x}, j \in S_{y}, \text { if } p_{i j}=1, \text { then } x \leq y \\
t\left(S_{k}\right) \leq c, k=1,2, \ldots, m
\end{array}\right.
$$

The product, resources and process of the automobile mixed-model assembly line are the key factors affecting the efficiency of the assembly line. The existing literature mainly considers the optimization of the process, but ignores the interaction between the resources, the products and the process. For the optimization and simulation of the assembly line, the following constraints shall be considered:

(1) A processing task must be taken in charge by a worker, the worker's workload cannot exceed the pre-set work tempo, and the maximum number of workers shall be set for the assembly work:

$$
\left\{\begin{array}{l}
\sum_{k \in K} \sum_{m \in M} x_{i k m}=1, \forall i \in I \\
\sum_{i \in I} x_{i k m} \bar{t}_{i} \leq y_{k m} C, \forall k \in K, \forall m \in M \\
\sum_{m \in M} y_{k m} \leq s_{k}^{\max }, \forall k \in K
\end{array}\right.
$$

(2) All the automotive components must be processed in the pre-planned order, and there are coupling constraint, co-location constraint and non-identical worker operating constraint between two adjacent tasks.

$$
\left\{\begin{array}{c}
\sum_{k=v+1}^{|k|} \sum_{m \in M} x_{j k m} \leq 1-\sum_{k=1}^{v} \sum_{m \in M} x_{i k m}, \forall v=1, \ldots, k-1, \text { if } p_{i j}=1 \\
x_{i k m}=x_{j k m} \forall i, j \in I, k \in K, m \in M \text { if } r_{i j}^{a d j}=1 \text { or } r_{i j}^{s t}=1 \\
\sum_{m \in M} x_{i k m}=\sum_{m \in M} x_{j k m} \forall i, j \in I, k \in K, m \in M \text { if } r_{i j}^{s s}=1
\end{array}\right.
$$

(3) If the task $i$ is assigned to a certain equipment $k$ for processing, and the processing tool is 1 , the constraint condition must be set as 1 and must be in the range of the equipment $k$ :

$$
Q_{i t}^{u}\left(\sum_{m \in M} x_{i k m}\right) \leq Q_{k, b i, t}^{c} \forall i \in I, k \in K, t \in T
$$

(4) If equipment or a processing area is inaccessible for a period of time, all processing parts shall not be assigned to the area or the secondary equipment:

$$
x_{i k m}=0 \quad \forall i \in I, k \in K, m \in M \text { if } A_{k m}^{m}=0
$$


(5) The volume of the processed products assigned to a particular device shall not exceed the maximum allowable volume of the device.

$$
\sum_{i}^{n} D_{i} \leq D_{v} \quad \forall i \in I
$$

\section{GENETIC ALGORITHM-BASED MODEL OPTIMIZATION}

\subsection{Development of the optimization model}

The optimization of automobile mixed assembly line is a typical problem of solving multiobjective optimal solution set. In order to reduce the amount of calculation, generally the problem of solving multi-objective optimal solution set is transformed to the problem of solving the weighted optimal solution of all targets. However, since the unit or dimension of various objective functions is different, the solution set obtained using this method has flaws; therefore, an improved genetic algorithm is put forward to seek the optimized objective function of the automobile mixed assembly line.

First, the selection operator $p(H)$ of the genetic algorithm is improved and after the fitness function is added, the following equation is obtained:

$$
p(H)=\frac{p_{0}(H)}{\sum_{G}\left(\frac{f(G)}{f(H)}\right)^{k} p_{k}(G)}
$$

The genetic algorithm uses the fitness function to solve the optimal solution. First, initialize the parameters, and select the parent individuals. When the high quality offspring is generated, access each individual in the collection of offspring and randomly select one for compile operation. Calculate its fitness value and judge whether it can serve as the optimal solution based on Metropolis principle. In each round of iteration, the constraints from Eqs. (3) to (7) will be imposed to make the selected high-quality individuals of each generation meet all the constraints, so that the objective function to be solved will not mutate or is not locally optimal.



Figure 2: The whole algorithm flow chart of improved genetic algorithm. 
The optimization process of the proposed improved genetic algorithm is shown in Fig. 2. It can be seen from Fig. 2 that the population and relevant calculation parameters shall be initialized first in the process. Then, evaluate the selected quality offspring individual in each round of iteration. If the convergence condition is met, output the results, otherwise linear inheritance will be adopted and the operation will repeat. The purpose of this operation is to guarantee the survival of the high quality offspring. Using the simulated annealing algorithm updates the original collection of high-quality offspring. Reselect the optimal solution after multiple iterative updates and output the results finally.

The formulas of the improved crossover probability $P_{d}$ and mutation probability can be expressed as:

$$
\begin{aligned}
& p_{d}=\left\{\begin{array}{l}
\rho \frac{k 1\left(f_{\max }-f^{\prime}\right)}{f_{\max }-f_{\text {avg }}}, f^{\prime} \geq f_{\text {avg }}, \rho \leq \delta \\
(1-\rho) \frac{k 1\left(f_{\max }-f^{\prime}\right)}{f_{\text {max }}-f_{\text {avg }}}, f^{\prime} \geq f_{\text {avg }}, \rho>\delta \\
\rho k 2, f^{\prime}<f_{\text {avg }}, \rho \leq \delta \\
(1-\rho) k 2, f^{\prime}<f_{\text {avg }}, \rho>\delta
\end{array}\right. \\
& P_{m}=\left\{\begin{array}{c}
\sqrt[l]{\frac{1}{n} \rho}, \rho \leq \delta \\
(1-\rho) \sqrt[l]{\frac{1}{n}}, \rho>\delta
\end{array}\right.
\end{aligned}
$$

$\rho$ is the population density; $f_{\text {avg }}$ and $f_{\max }$ refer to average fitness and the maximum fitness respectively; $\delta$ is the specified mode length; $k_{1}$ and $k_{2}$ are correlation indexes.

\subsection{Performance test analysis of the model}

The following indicators are used as the evaluation criteria to measure the superiority of this algorithm proposed in this paper. Optimal performance:

$$
E_{m, o n-l i n e}=\frac{c_{b}(k)-c^{*}}{c^{*}} \times 100 \%
$$

$c_{b}(k)$ is the optimal value of the $k^{\text {th }}$ iteration; $c$ is the optimal solution.

Robustness:

$$
E_{f, \text { offline }}=\frac{c_{a}-c^{*}}{c^{*}} \times 100 \%
$$

$c_{a}$ is the average value worked out after multiple calculations of iterations. $E_{f}$ is the volatility.

The De-Jong function is used to compare the convergence of the improved genetic algorithm proposed in this paper and the traditional genetic algorithm, as shown in Fig. 3. It can be seen from the figure that when the initial population of the standard genetic algorithm is 150 , the local optimal solution occurs only after three times of iteration. When the size of population increases to 450 , the accuracy of the calculation result increases too, but it still does not converge to the analytical solution. In this improved algorithm, proposed in this paper, as long as the population quantity reaches 50 , the local prematurity phenomenon can be restrained effectively, and when the population quantity expands to 200 , the globally optimal solution has converged to the analytical solution, suggesting the superiority of the improved algorithm proposed in this paper. 


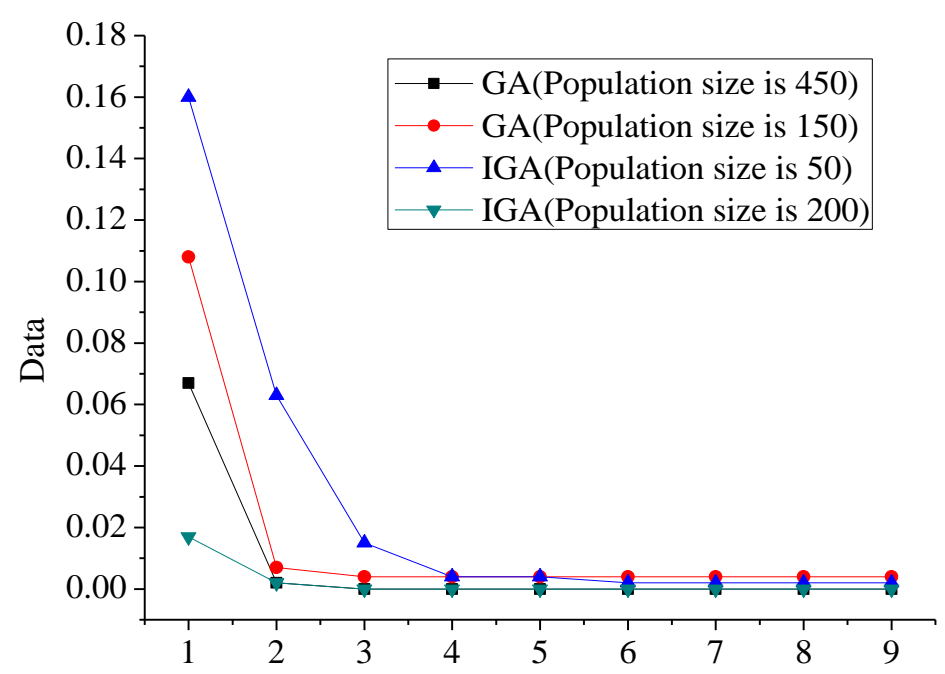

Figure 3: Convergence curve of standard genetic algorithm and improved genetic algorithm.

Furthermore, the genetic algorithm test standard on the German website (ALB.Mansci.de) is used to test the improved genetic algorithm established in this paper. There are 12 test items in total. Take the average value of 20 times of calculation as the output result, and compare the average tempo of the assembly line CT, the maximum load of the assembly line and the average time consumption of CPU of the standard genetic algorithm and improved genetic algorithm. The comparison results are shown in Table I.

Table I: Scheduled starting and finishing times of activities.

\begin{tabular}{|c|c|c|c|c|c|c|c|}
\hline \multirow{2}{*}{$\begin{array}{c}\text { Test } \\
\text { problem }\end{array}$} & Task & \multicolumn{3}{|c|}{ Standard genetic algorithm } & \multicolumn{3}{c|}{ Improved genetic algorithm } \\
\cline { 3 - 8 } & scale & $\boldsymbol{C}_{\boldsymbol{T}}$ & Max Load & CPU & $\boldsymbol{C}_{\boldsymbol{T}}$ & Max Load & CPU \\
\hline Jae & 7 & 8.09 & 329.45 & 3.72 & 8.09 & 349.65 & 2.68 \\
Hes & 10 & 154.2 & 10009.63 & 6.04 & 149.3 & 10078.69 & 5.15 \\
Gun & 13 & 59.44 & 5134.28 & 6.75 & 57.27 & 5140.56 & 5.88 \\
Jak & 26 & 9.15 & 420.38 & 3.9 & 8.76 & 457.71 & 3.48 \\
Bow & 28 & 20.59 & 779.17 & 2.66 & 20.58 & 782.36 & 1.84 \\
Kil & 33 & 78.47 & 5220.87 & 7.91 & 48.03 & 5186.46 & 7.29 \\
Lut-1 & 37 & 1998 & 143387.29 & 4.76 & 1889.8 & 145017.52 & 3.95 \\
Lut-2 & 47 & 29.11 & 4604.32 & 9.94 & 29.16 & 4602.72 & 8.50 \\
Bux & 54 & 33.55 & 3120.24 & 6.21 & 33.45 & 3220.86 & 5.23 \\
Hah & 82 & 2498 & 137834.22 & 7.83 & 2446.6 & 138078.49 & 7.96 \\
Bar & 88 & 590.2 & 55634.84 & 17.62 & 574.3 & 54298.84 & 15.69 \\
Arc & 149 & 5705 & 654682 & 113.60 & 4995 & 655843 & 13.05 \\
\hline
\end{tabular}

It can be seen from the table that compared with traditional genetic algorithm, the time consumption of CPU in the proposed improved genetic algorithm is much less, and its maximum load is larger, so the improved genetic algorithm has more advantages.

\section{ENGINEERING PRACTICE ANALYSIS}

Based on the mathematical model and improved genetic algorithm of the automobile mixed assembly line established in the preceding part of this paper, this section analyses the feasibility and superiority of the established model through the assembly of the automobile doors. The automobile door is an important part of automobile assembly, and the assembly quality of the door directly affects the sound insulation, safety and beauty of the automobile. Fig. 4 shows the technical process of the vehicle assembly. It can be seen from the figure that 
the assembly of door is the most complicated part, involving the interworking of multiple processing stages and assembly lines. Reasonable and highly effective mixed assembly production of automobile door can significantly improve the production efficiency of the factory.

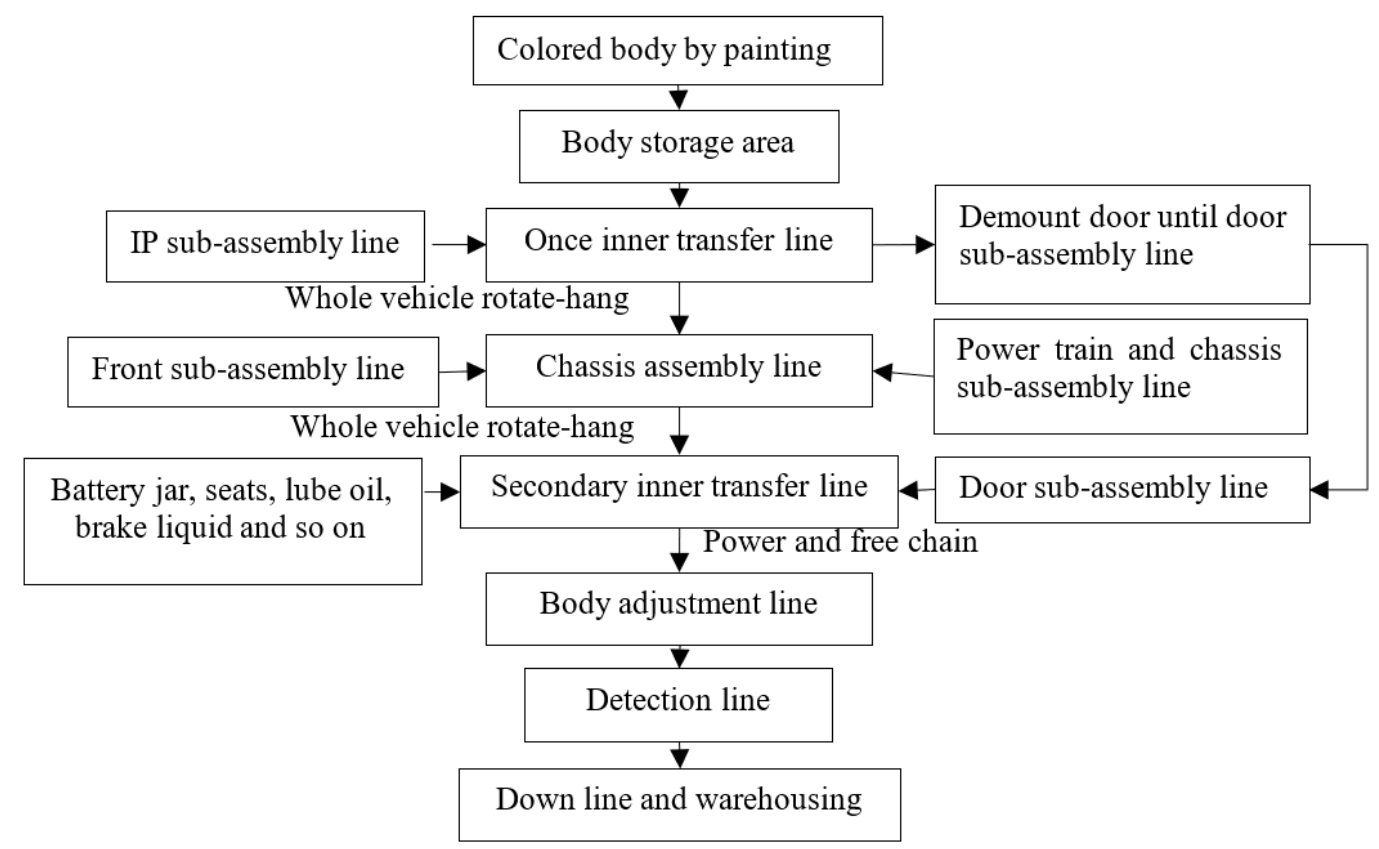

Figure 4: Vehicle general assembly process flow chart.

Select the mixed assembly line of some automobile door to make analysis. There are 140 assembly procedures in total for the door. Make the door pass each processing equipment in order based on the planned flow path of the assembly line. The assembly position can be divided into lower position assembly, middle position assembly and higher position assembly based on the assembly technology. 1-2 workers are assigned before each equipment.

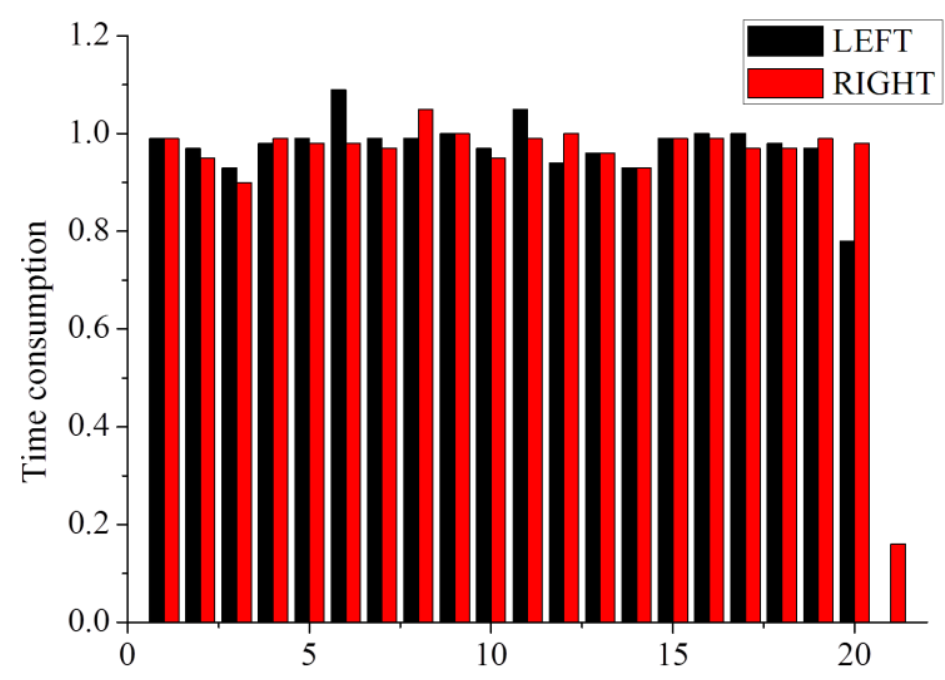

Figure 5: Analysis results of standard form door product.

Taking the assembly of a single type of auto door as an example, imagine there is only one kind of product, the auto door, in the whole production assembly line. The balance analysis of the door in the assembly line is shown in Fig. 5. Fig. 6 shows the optimal fitting convergence curve and the average fitting convergence curve of the auto door assembly line in the simulation algorithm. As seen in Fig. 5, the balance analysis requires 42 workers in 
total, and the overall balance efficiency is about $92 \%$, reaching the standard for leaving factory. As shown in Fig. 6, when the number of iterations reaches 55, the average fitting curve can obtain the optimal convergence value, and the optimal fitting curve achieves this result through 50 iterations.

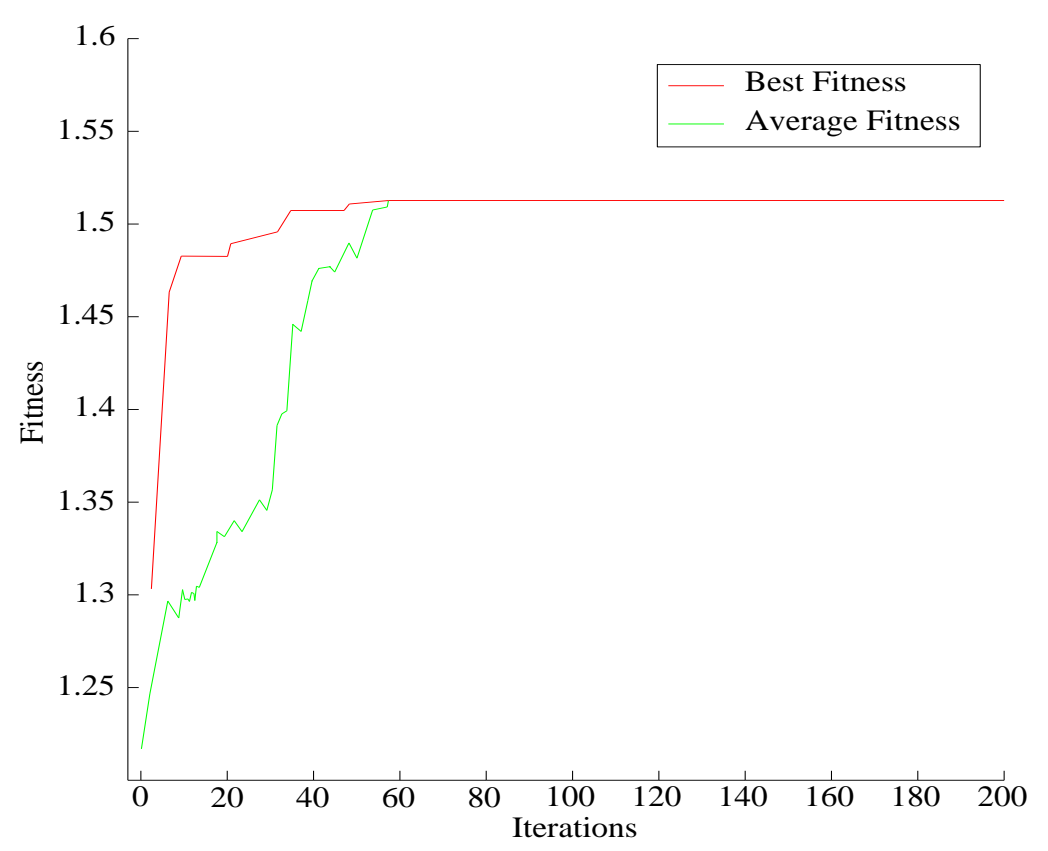

Figure 6: Convergence curves of standard form door product analysis algorithms.

Fig. 7 shows the relationship between the proportion of certain kind of auto door put into the whole assembly line and the assembly time consuming. It can be seen from the figure that when the proportion gradually rises, the overall time consumption of the whole assembly line is shorter and shorter, because the larger the proportion of single product is, the more likely it is to realize mass production. And the more varieties of products on the assembly line there are, the more complicate the assembly line planning is and the more the overall time consumption is. It can be seen from Fig. 8 that when the proportion of a single product that was put into production is large, the balance efficiency of the mixed assembly line presents a "U-shape" variation trend, first decreasing and then increasing. The balance efficiency is the lowest when the proportion is $90 \%$.

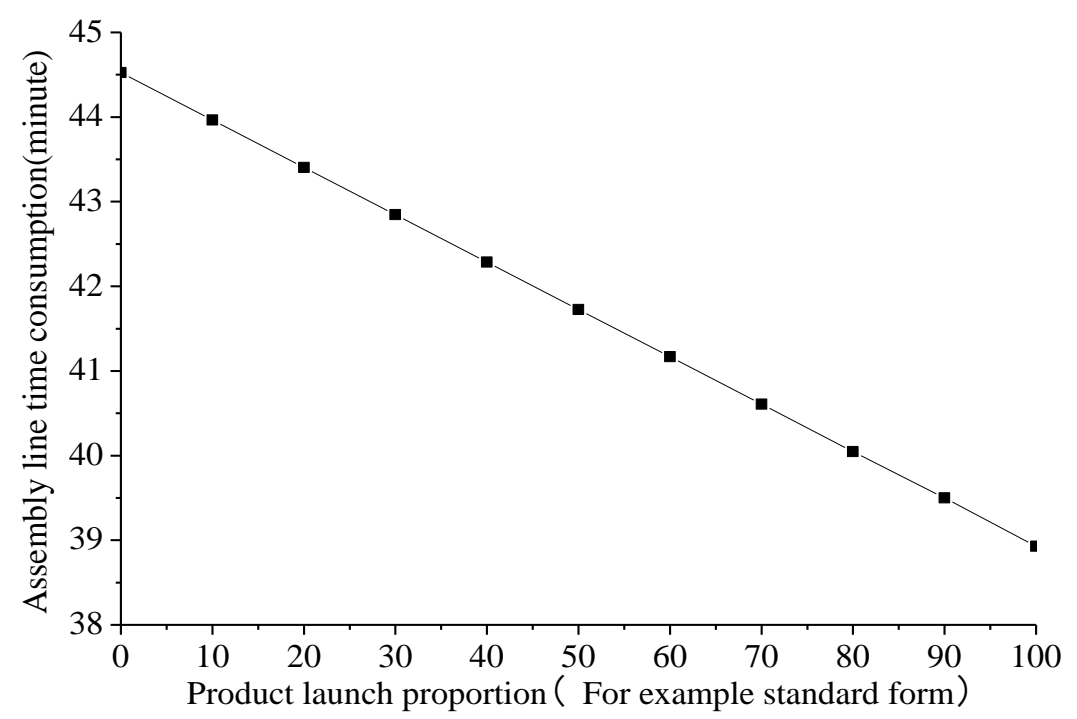

Figure 7: Change curve of the operation time of the assembly line following the launch proportion. 


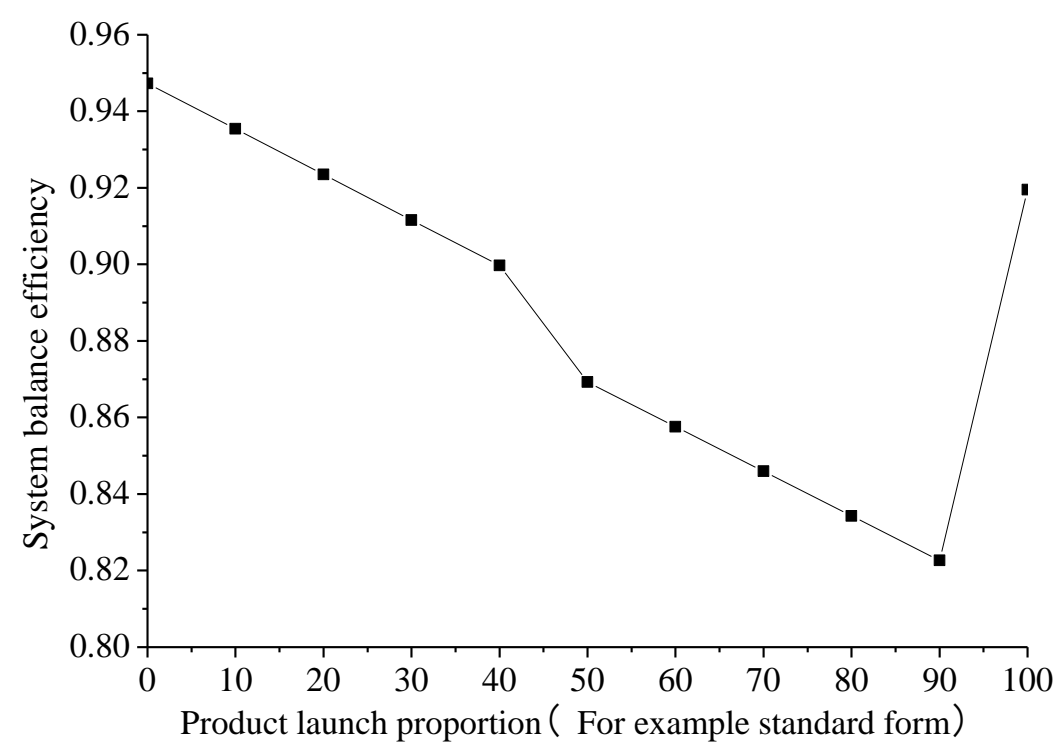

Figure 8: Change curve of the balance efficiency of assembly line following the launch proportion.

Fig. 9 shows the assembly time used to assemble different number of different products when different number of workers is assigned to independent equipment. It can be seen from the figure that the larger the assembly quantity, the more time is consumed. However, the growth of worker number does not have an obvious impact on the assembly time consumption, which rises slightly.

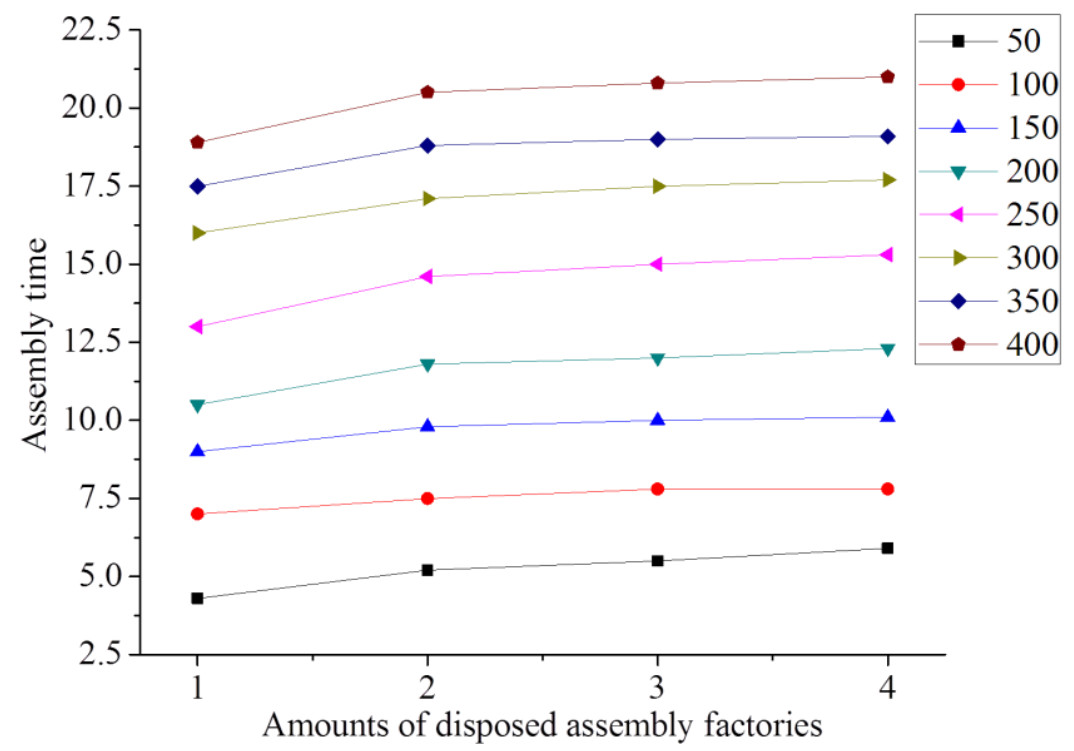

Figure 9: Time consumption curve of mixed-model assembly factories disposition.

\section{CONCLUSIONS}

To solve the problems in planning and design of automobile mixed-model assembly line, this paper puts forward the improved genetic algorithm-based equilibrium optimization algorithm for the automobile mixed assembly line and establishes corresponding theoretical model. The convergence and feasibility of the model are analysed, and the optimization model presented in this paper is verified through the assembling of an automobile door on the actual assembly line. The research conclusions are as follows:

(1) The optimized scheduling mathematical model under multiple constrains of the automobile assembly line was established and improvements were made to the traditional 
genetic algorithm. Self-adaptive genetic operator was added to the original model. The performance verification indicated that the time consumption of CPU in the proposed improved algorithm is much less, and its maximum load is larger, so it has better convergence compared with traditional genetic algorithm.

(2) The improved optimal algorithm of automobile mixed ASSEMBLY LINE was verified taking into consideration such constraint conditions as the proportion of a single product put into assembly line, staffing, and balance of the left door and right door. It is found that the overall balance efficiency is about $92 \%$, reaching the standard for leaving factory. When the proportion of a single product that was put into production gradually rises, the overall time-consumption of the whole assembly line becomes shorter and shorter and the balance efficiency of the mixed assembly line presents a "U-shape" variation trend, first decreasing and then increasing. The growth of workers doesn't have an obvious impact on the assembling time consumption.

\section{REFERENCES}

[1] Yong, J.; Gao, F.; Ding, N.; He, Y. (2017). Design and validation of an electro-hydraulic brake system using hardware-in-the-loop real-time simulation, International Journal of Automotive Technology, Vol. 18, No. 4, 603-612, doi:10.1007/s12239-017-0060-2

[2] Park, K.; Heo, S.-J. (2004). A study on the brake-by-wire system using hardware-in-the-loop simulation, International Journal of Vehicle Design, Vol. 36, No. 1, 38-49, doi:10.1504/ ijvd.2004.005319

[3] Mamcic, S.; Bogdevicius, M. (2010). Simulation of dynamic processes in hydraulic accumulators, Transport, Vol. 25, No. 2, 215-221, doi:10.3846/transport.2010.26

[4] Hui, S.; Lifu, Y.; Junqing, J. (2010). Hydraulic/electric synergy system (HESS) design for heavy hybrid vehicles, Energy, Vol. 35, No. 12, 5328-5335, doi:10.1016/j.energy.2010.07.027

[5] Hui, S.; Lifu, Y.; Junqing, J., Yanling, L. (2011). Control strategy of hydraulic/electric synergy system in heavy hybrid vehicles, Energy Conversion and Management, Vol. 52, No. 1, 668-674, doi:10.1016/j.enconman.2010.07.045

[6] Deng, X. L.; Wang, J. C. (2017). Research on the manufacturing of mechanical parts based on the theory of space symmetry group, Academic Journal of Manufacturing Engineering, Vol. 15, No. 1, 64-71

[7] Huang, W. S. (2017). Fixed control system of assembly robot based on vision control, Academic Journal of Manufacturing Engineering, Vol. 15, No. 3, 60-65

[8] Ramesh Kumar, L.; Padmanaban, K. P.; Balamurugan, C. (2016). Optimal tolerance allocation in a complex assembly using evolutionary algorithms, International Journal of Simulation Modelling, Vol. 15, No. 1, 121-132, doi:10.2507/IJSIMM15(1)10.331

[9] Chutima, P.; Chimklai, P. (2012). Multi-objective two-sided mixed-model assembly line balancing using particle swarm optimisation with negative knowledge, Computers \& Industrial Engineering, Vol. 62, No. 1, 39-55, doi:10.1016/j.cie.2011.08.015

[10] Li, D.; Zhang, C.; Shao, X.; Lin, W. (2016). A multi-objective TLBO algorithm for balancing two-sided assembly line with multiple constraints, Journal of Intelligent Manufacturing, Vol. 27, No. 4, 725-739, doi:10.1007/s10845-014-0919-2

[11] Sung, C. S.; Kim, Y. H.; Yoon, S. H. (2000). A problem reduction and decomposition approach for scheduling for a flowshop of batch processing machines, European Journal of Operational Research, Vol. 121, No. 1, 179-192, doi:10.1016/s0377-2217(99)00031-4

[12] Zhang, Q.; Manier, H.; Manier, M.-A. (2012). A hybrid metaheuristic algorithm for flexible jobshop scheduling problems with transportation constraints, Proceedings of the $14^{\text {th }}$ Annual Conference on Genetic and Evolutionary Computation, 441-448, doi:10.1145/2330163.2330226

[13] Futatsuishi, Y.; Watanabe, I. (1996). A study of multistage flow shop scheduling problem with alternative job assignments, Journal of Japan Industrial Management Association, Vol. 46, No. 6, 590-598 
[14] Futatsuishi, Y.; Watanabe, I.; Nakanishi, T. (2002). A study of the multi-stage flowshop scheduling problem with alternative operation assignments, Mathematics and Computers in Simulation, Vol. 59, No. 1-3, 73-79, doi:10.1016/s0378-4754(01)00394-9

[15] Scholl, A.; Becker, C. (2006). State-of-the-art exact and heuristic solution procedures for simple assembly line balancing, European Journal of Operational Research, Vol. 168, No. 3, 666-693, doi:10.1016/j.ejor.2004.07.022

[16] Wang, B.; Guan, Z.; Li, D.; Zhang, C.; Chen, L. (2014). Two-sided assembly line balancing with operator number and task constraints: a hybrid imperialist competitive algorithm, The International Journal of Advanced Manufacturing Technology, Vol. 74, No. 5-8, 791-805, doi:10.1007/s00170-014-5816-5

[17] Wang, L.-C.; Lin, Y.-C.; Lin, P. H. (2007). Dynamic mobile RFID-based supply chain control and management system in construction, Advanced Engineering Informatics, Vol. 21, No. 4, 377 390, doi: $10.1016 /$ j.aei.2006.09.003

[18] Delice, Y.; Aydoğan, E. K.; Özcan, U.; İlkay, M. S. (2017). A modified particle swarm optimization algorithm to mixed-model two-sided assembly line balancing, Journal of Intelligent Manufacturing, Vol. 28, No. 1, 23-36, doi:10.1007/s10845-014-0959-7

[19] Scholl, A.; Fliedner, M.; Boysen, N. (2010). ABSALOM: balancing assembly lines with assignment restrictions, European Journal of Operational Research, Vol. 200, No. 3, 688-701, doi:10.1016/j.ejor.2009.01.049

[20] Boysen, N.; Fliedner, M.; Scholl, A. (2009). Sequencing mixed-model assembly lines: survey, classification and model critique, European Journal of Operational Research, Vol. 192, No. 2, 349-373, doi:10.1016/j.ejor.2007.09.013

[21] Fazlollahtabar, H.; Hajmohammadi, H.; Es'Haghzadeh, A. (2011). A heuristic methodology for assembly line balancing considering stochastic time and validity testing, The International Journal of Advanced Manufacturing Technology, Vol. 52, No. 1-4, 311-320, doi:10.1007/ s00170-010-2708-1

[22] Liu, S. B.; Ong, H. L.; Huang, H. C. (2005). A bidirectional heuristic for stochastic assembly line balancing Type II problem, The International Journal of Advanced Manufacturing Technology, Vol. 25, No. 1-2, 71-77, doi:10.1007/s00170-003-1833-5

[23] Sabuncuoglu, I.; Erel, E.; Tanyer, M. (2000). Assembly line balancing using genetic algorithms, Journal of Intelligent Manufacturing, Vol. 11, No. 3, 295-310, doi:10.1023/A:1008923410076 